\title{
Optimalisasi Antrian Menggunakan Metode Single Channel Single Phase (Studi Kasus DR. Reksodiwiryo Padang)
}

\author{
Yeyi Gusla Nengsih \\ Program Studi D-III Perekam Medis dan Informasi Kesehatan, Universitas Imelda Medan
}

\begin{tabular}{l}
\hline Article Info \\
\hline Article history: \\
Received Feb 18, 2020 \\
Revised Feb 25, 2020 \\
Accepted Feb28, 2020
\end{tabular}

Keywords:

Patient Satisfaction

Queue System

Single Channel Single Phase

Method

Padang RST

\begin{abstract}
ABSTRAK
Queue is an event where customers have to wait their turn to get service. The process of queuing at the Padang Army Hospital pharmacy is a problem that is often a complaint for patients. To overcome this problem a queuing system method is needed in order to get the performance of the queuing model. So as to provide an overview and solutions to improve service performance in the process of taking drugs at the Padang Army Hospital dispensary. The Queuing model used is the Single Channel Single Phase queue model which has one path and one service that is flowed by a single queue. The variables to be observed are interarrival time, service start time and service finish time by assuming poisson distribution patterns. The results of this study will be obtained the longest server busy time is $94.12 \%$, the average number of patients in the longest queue per period (Lq) is 15 patients, the average number of patients in the longest system period (Ls) is 16 patients, patient time in the longest system of time period (Ws) which is 60 minutes, patient time is in the longest queue per period of time $(\mathrm{Wq})$ which is 56.472 minutes.
\end{abstract}

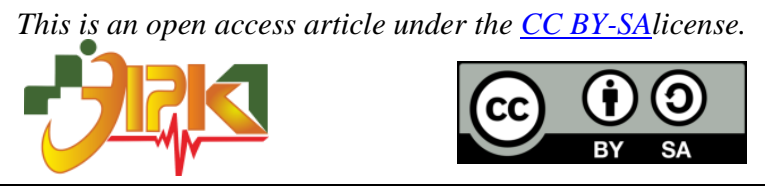

\section{Corresponding Author:}

Yeyi Gusla Nengsih,

Program Studi D-III Perekam Medis dan Informasi Kesehatan,

Universitas Imelda Medan,

Jl. Bilal No. 52 Kelurahan Pulo Brayan Darat I Kecamatan Medan Timur, Medan - Sumatera Utara.

Email: yeyigusla22@gmail.com

\section{PENDAHULUAN}

Dunia teknologi informasi dan komputer yang berkembang pesat saat ini, sangat diperlukan untuk mendapatkan informasi agar pekerjaan dapat direalisasikan secara efektif dan efesien serta mempermudah tugas manusia, tidak terkecuali dalam bidang kesehatan salah satunya proses pengambilan obat yang dilakukan di Rumah Sakit Tentara Padang. Disadari atau tidak, setiap manusia sering kali dihadapkan pada situasi yang sama yaitu mengantri untuk mendapatkan pelayanan. Antri yang panjang akan menimbulkan citra yang kurang baik pada pasien dan akan mengalami kerugian karena sedikitnya keuntungan.

Tanggung jawab utama dari unit Rumah Sakit Tentara Padang adalah menyediakan dan membuat obat-obatan menurut resep dokter yang disampaikan ke loket pengambilan obat, dan juga bertanggung jawab atas kecepatan serta ketepatan dalam pelayanan. Apalagi rumah sakit yang begitu besar dengan sedikit staff, solusi untuk meningkatkan layanan rumah sakit dan kepuasan pasien sangat diperlukan. Setelah di survey secara langsung ke Rumah Sakit Tentara Padang tersebut, ternyata sering terjadi penungguan orang cukup banyak diloket 
pengambilan obat terutama pada saat jam-jam sibuk. Penelitian sebelumnya yang berkaitan dengan waktu tunggu atau antrian menyatakan sangat membantu pihak manajemen rumah sakit dalam memenuhi kepuasan pelayanan di rumah sakit (E. Simanjuntak, 2016; M. Simanjuntak, 2016).

Untuk memecahkan masalah analisis dan sintesis pada kasus pertama harus mengetahui tingkat intensitas pelayanan $(\mathrm{p})$, probabilitas $\mathrm{p} 0$, rata-rata panjang antrian, waktu rata-rata menunggu untuk dilayani, waktu setiap pasien selama dalam sistem, waktu setiap pasien selama dalam antrian dan tingkat kedatangan di asumsikan sebagai distribusi poisson dengan menggunakan metode antrian single channel single phase.

\section{METODE PENELITIAN}

\section{Struktur Antrian}

Struktur antrian terbagi dalam beberapa model antara lain :

1. Single channel - single phase

Single channel merupakan sistem pelayanan yang memiliki satu jalur atau satu pelayanan.Sedangkan single phase adalah hanya memiliki satu stasiun pelayanan sehingga setelah menerima pelayanan dapat langsung keluar dari sistem antrian. Dan dapat dilihat pada gambar 1 dibawah ini :

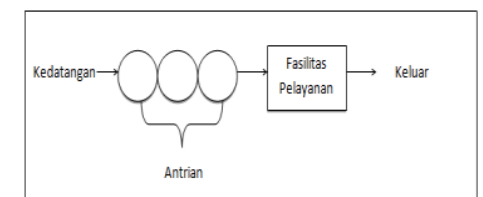

\section{Gambar 1. Single Channel - Single Phase}

2. Single channel - multi phase

Single channel multi phase atau jalur tunggal beberapa tahap pelayanan yaitu sistem antrian yang hanya ada satu jalur antrian namun ada dua atau lebih pelayanan yang dilaksanakan secara berurutan.

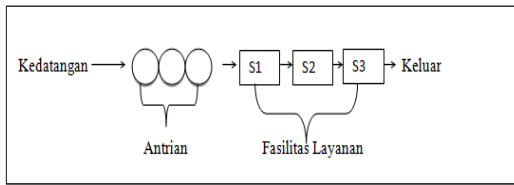

\section{Gambar 2. Single Channel - Multi Phase}

3. Multi channel - single phase

Multiple channel single phaseatau jalur ganda satu tahap pelayanan yaitu sistem yang hanya terdapat satu jalur antrian dengan dua ataulebih fasilitas pelayanan.

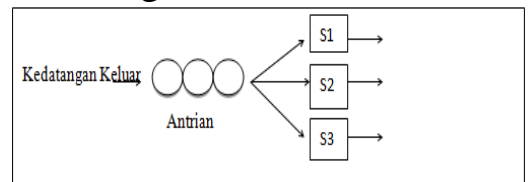

\section{Gambar 3. Multi Channel - Single Phase}

4. Multi channel - multi phase

Multiple channel multi phaseatau jalur ganda beberapa tahap pelayanan yaitu sistem yang terdapat beberapa jalur antrian dengan beberapa tahap pelayanan.

\section{Kriteria Antrian}

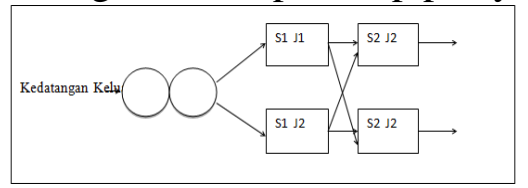

\section{Gambar 4. Multi Channel - Multiphase}


Ada beberapa kriteria atau notasi antrian yang harus kita ketahui adalah sebagai berikut:

Tabel 1. Notasi Antrian

\begin{tabular}{cl}
\hline Notasi & \multicolumn{1}{c}{ Penjelasan } \\
\hline$\lambda$ & Tingkat kedatangan rata-rata \\
$1 / \lambda$ & Rata-rata waktu antar kedatangan \\
$\mu$ & Tingkat pelayanan rata-rata \\
$1 / \mu$ & Waktu pelayanan rata-rata \\
$\mathrm{N}$ & Jumlah individu dalam sistem pada suatu waktu \\
$\mathrm{Lq}$ & Rata-rata jumlah individu dalam antrian \\
$\mathrm{Ls}$ & Rata-rata jumlah individu dalam system \\
$\mathrm{Wq}$ & Waktu individu berada dalam antrian \\
$\mathrm{Ws}$ & Waktu rata-rata yang dihabiskan dalam system \\
$\mathrm{W}$ & Tingkat pengganguran server \\
$\mathrm{K}$ & Tingkat kesibukan server \\
$\mathrm{P}$ & Tingkat intensitas fasilitas pelayanan \\
$\mathrm{Q}$ & Kepanjangan maksimum sistem \\
$\mathrm{P}_{\mathrm{n}}$ & Probabilitas jumlah dan individu dalam system \\
$\mathrm{P}_{\mathrm{o}}$ & Probabilitas tidak ada individu dalam system \\
\hline
\end{tabular}

\section{Model Antrian Single Channel-Single Phase (M/M/1)}

Persamaan yang digunakan dalam menganalisis antrian pada model antrian single channel-single phase adalah sebagai berikut :

1. Probabilitas terdapat 0 orang dalam sistem

$\mathrm{P} 0=1-\mathrm{P}$

2. Tingkat kesibukan server

$$
\mathrm{P}=\frac{\lambda}{\mu} \text {....... }
$$

3. Rata-rata pasien dalam sistem

$$
\mathrm{Ls}=\frac{\mathrm{P}}{1-\mathrm{P}} \text {. }
$$

4. Rata-rata pasien dalam antrian

$$
\mathrm{Lq}=\frac{\lambda{ }^{2}}{\mu(\mu-\lambda)}
$$

5. Waktu yang dibutuhkan pasien dalam sistem

$$
\mathrm{Ws}=\frac{1}{\mu-\lambda} \text {. }
$$

6. Waktu yang diperlukan pasien dalam antrian

$\mathrm{Wq}=\frac{\lambda}{\mu(\mu-\lambda)}$.

\section{A. Jenis Penelitian}

Dari kasus yang ada pada Rumah Sakit Tentara Padang penulis memilih target untuk menyelesaikan masalah menggunakan metodologi penelitian yang dilakukan secara sistematik yaitu sebagai pedoman dalam pelaksanaan penelitian ini, agar hasil yang dicapai tidak menyimpang dari tujuan yang telah ditentukan sebelumnya. Adapun penelitian ini di awali dengan mengidentifikasi masalah yakni menggunakan metode antrian single channel-single phase guna mengoptimalisasi tingkat pelayanan terhadap pasien serta didukung dengan bahasa pemrograman visual basic.

Pengumpulan data dilakukan dengan melakukan observasi ke lapangan sehingga menggambarkan realitas masalah antrian yang sebenarnya. Data yang diambil adalah 
data primer yaitu dengan menghitung waktu kedatangan pasien, mulai proses dan selesai proses yang terjadi pada Rumah Sakit Tentara Padang. Pengumpulan data dilakukan dengan mempelajari dan menelaah jurnal, buku dan tulisan yang berhubungan dengan penelitian ini. Pelaksanan observasi lapangan dilakukan selama 3hari yang dipilih yaitu tanggal 20 - 22 juni 2018 yang dilakukan pada jam 08.00 18.00 akan tetapi yang akan digunakan dan di olah sebagai sampel dalam penelitian ini khusus pada hari rabu.

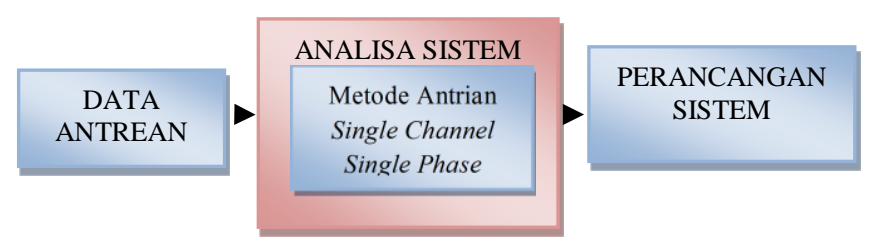

Gambar 5. Kerangka Kerja Penelitian

\section{HASIL DAN PEMBAHASAN}

\subsection{Hasil}

Dari perhitungan di atas maka dapat diperoleh analisis antrian model $\mathrm{m} / \mathrm{m} / 1$ atau metode antrian single channel-single phasepada Rumah Sakit TentaraPadang dalam periode tertentu sebagai berikut :

Tabel 2. Hasil Kinerja Sistem Antrian

\begin{tabular}{ccccccc}
\hline Per & \multicolumn{7}{c}{ Kinerja sistem antrian } \\
\cline { 2 - 7 } Waktu & $\mathrm{P}$ & $\mathrm{P} 0$ & $\mathrm{Ls}$ & $\mathrm{Lq}$ & $\mathrm{Ws}$ & $\mathrm{Wq}$ \\
$08.00-09.00$ & 0,615 & 0,385 & 1,6002 & 0,9847 & 12 & 7,4 \\
$09.00-10.00$ & 0,539 & 0,462 & 1,1669 & 0,6283 & 10 & 5,388 \\
$10.00-11.00$ & 0,75 & 0,25 & 3 & 2,25 & 15 & 11,25 \\
$11.00-12.00$ & 0,864 & 0,136 & 6,3368 & 5,4697 & 20 & 17,27 \\
$12.00-13.00$ & 0,914 & 0,0869 & 10,5075 & 9,5870 & 30 & 27,39 \\
$13.00-14.00$ & 0,895 & 0,1052 & 8,5058 & 7,6053 & 30 & 26,844 \\
$14.00-15.00$ & 0,9412 & 0,0588 & 16,0069 & 15,0589 & 60 & 56,472 \\
$15.00-16.00$ & 0,8 & 0,2 & 4 & 3,2 & 60 & 48 \\
\hline
\end{tabular}

Rangkaian percobaan dari hasil kinerja sistem antrian diatas dengan menggunakan perangkat lunak Visual Basic dapat dilihat pada gambar 8 dan gambar 9 yaitu :

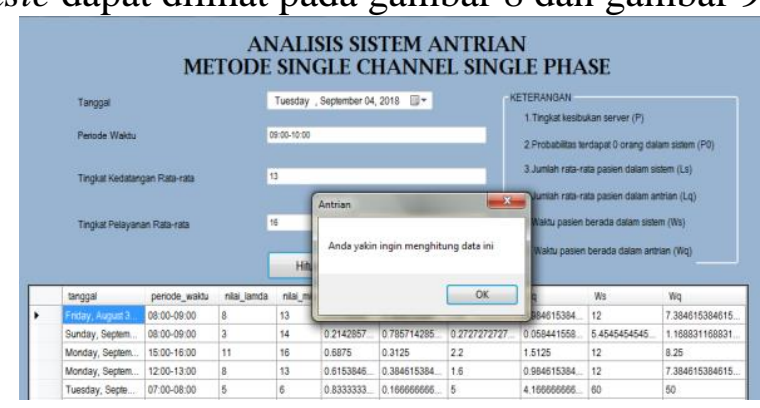

Gambar 6. Form Pengujian Metode 


\begin{tabular}{|c|c|c|c|c|c|c|c|c|c|}
\hline \multicolumn{10}{|c|}{$\begin{array}{l}\text { Moded Antrian Single Channel Single Phase } \\
\text { RST. Reksowididiry Padang }\end{array}$} \\
\hline \multicolumn{10}{|c|}{ LAPORAN HASLL HTUNGAN PREDIKSI } \\
\hline Tanggal & Periode Waktu & Nilai Lamda & Nilai Miu & $\mathrm{p}$ & Po & Ls & Lq & Ws & wq \\
\hline Finday, August 31, 2018 & $08: 00-09 \cdot 00$ & 8 & 13 & 0.62 & 0.38 & 1.60 & 0.98 & 1200 & 7.38 \\
\hline Sunday, September 02,2018 & $08.00-09.00$ & 3 & 14 & 0.22 & 0.79 & 0.27 & 0.06 & 5.45 & 1.17 \\
\hline Monday, September 03, 2018 & $15: 00-16: 00$ & 11 & 16 & 0.69 & 0.31 & 220 & 1.51 & 1200 & 825 \\
\hline Monday, September 03, 2018 & $1200-13: 00$ & 8 & 13 & 0.62 & 0.38 & 1.60 & 0.98 & 1200 & 738 \\
\hline Tuesday, September 04,2018 & 07:00.08:00 & 5 & 6 & $0.8:$ & 0.17 & 5.00 & 4.17 & 6000 & 50.00 \\
\hline Tuesday, September O4, 2018 & 09:00-10:00 & 13 & 16 & 0.81 & 0.19 & 4.33 & 3.52 & 20.00 & 16.25 \\
\hline
\end{tabular}

Gambar 7. Laporan Hasil Hitungan Prediksi

\subsection{Pembahasan}

Metode antrian single channel-single phese adalah pelayanan yang memiliki satu jalur dan satu pelayanan sehingga setelah menerima pelayanan dapat langsung keluar dari sistem antrian. Adapun langkah-langkah metode antrian single channel single phase dapat dilihat pada algoritma berikut ini :
Algoritma Proses Antrian Single
Channel Single Phase :
1. Perhitungan Service Time (Waktu layanan)
2. Perhitungan Time in Queu (Waktu dalam antrian)
3. Perhitungan Time in System (Waktu dalam sistem)
4. Hasil simulasi rata-rata waktu tunggu dalam antrian
5. Hasil simulasi rata-rata waktu tunggu dalam sistem
6. Analisa sistem antrian dengan model antrian single channel single phase atau $\mathrm{M} / \mathrm{M} / 1$
7. Hasil kinerja sistem antrian
8. Selesai

\section{Gambar 8. Langkah Metode Antrian Single Channel-Single Phase}

\section{Perhitungan Service Time (Waktu Layanan)}

Diketahui SET $=08.15$ SST $=08.09$

Untuk mencari perhitungan Service Time (ST) digunakan rumus :

$\mathrm{ST}=\mathrm{SET}-\mathrm{SST}$

$\mathrm{ST}=08.15-08.09=00.06$

\section{Perhitungan Time In Queu (Waktu Dalam Antrian)}

Diketahui SST $=08.09$ AT $=07.19$

Untuk mencari perhitungan Time In Queu (TIQ) digunakan rumus :

TIQ $=$ SST - AT

$\mathrm{TIQ}=08.09-07.19=00.50$

Perhitungan Time In System (Waktu Dalam Sistem)

Diketahui SET $=08.15$ AT $=07.19$ 
Untuk mencari perhitungan Time In System (TIS) digunakan rumus :

TIS $=$ SET - AT

$\mathrm{TIS}=08.15-07.19=00.56$

Dari perhitungan yang dilakukan di atas, untuk lebih detail nya dapat dilihat pada gambar dibawah ini sebagai berikut :

\begin{tabular}{|l|c|c|c|c|c|c|c|}
\hline No & Hari / Tanggal & AT & SST & SET & ST & TIQ & TIS \\
\hline 4 & Rabu, 20 Juni 2018 & $07: 19$ & $08: 09$ & $08: 15$ & $00: 06$ & $00: 50$ & $00: 56$ \\
\hline 5 & Rabu, 20 Juni 2018 & $07: 22$ & $08: 15$ & $08: 23$ & $00: 08$ & $00: 53$ & $01: 01$ \\
\hline 6 & Rabu, 20 Juni 2018 & $07: 22$ & $08: 23$ & $08: 30$ & $00: 07$ & $01: 01$ & $01: 08$ \\
\hline 7 & Rabu, 20 Juni 2018 & $07: 23$ & $08: 30$ & $08: 34$ & $00: 04$ & $01: 07$ & $01: 11$ \\
\hline 8 & Rabu, 20 Juni 2018 & $07: 34$ & $08: 34$ & $08: 38$ & $00: 04$ & $01: 00$ & $01: 04$ \\
\hline 9 & Rabu, 20 Juni 2018 & $07: 36$ & $08: 38$ & $08: 42$ & $00: 04$ & $01: 02$ & $01: 06$ \\
\hline 10 & Rabu, 20 Juni 2018 & $07: 36$ & $08: 42$ & $08: 50$ & $00: 08$ & $01: 06$ & $01: 14$ \\
\hline 11 & Rabu, 20 Juni 2018 & $07: 38$ & $08: 50$ & $08: 54$ & $00: 04$ & $01: 12$ & $01: 16$ \\
\hline 12 & Rabu, 20 Juni 2018 & $07: 39$ & $08: 54$ & $08: 57$ & $00: 03$ & $01: 15$ & $01: 18$ \\
\hline 13 & Rabu, 20 Juni 2018 & $07: 39$ & $08: 57$ & $09: 00$ & $00: 03$ & $01: 18$ & $01: 21$ \\
\hline 14 & Rabu, 20 Juni 2018 & $07: 39$ & $09: 00$ & $09: 02$ & $00: 02$ & $01: 21$ & $01: 23$ \\
\hline 15 & Rabu, 20 Juni 2018 & $07: 41$ & $09: 02$ & $09: 04$ & $00: 02$ & $01: 21$ & $01: 23$ \\
\hline 16 & Rabu, 20 Juni 2018 & $07: 42$ & $09: 04$ & $09: 08$ & $00: 04$ & $01: 22$ & $01: 26$ \\
\hline
\end{tabular}

Gambar 9. Perhitungan ST, TIQ, TIS

\section{Hasil Simulasi Rata-Rata Waktu Tunggu Dalam Antrian}

Dari perhitungan diatas, maka dapat dilakukan perhitungan untuk mengetahui waktu rata-rata pasien menunggu dalam antrian yaitu 84:08 $=5048$ menit/128 Pasien $=39,5$ Menit.

\section{Hasil Simulasi Rata-Rata Waktu Tunggu Dalam Sistem}

Sedangkan perhitungan untuk mengetahui waktu rata-rata pasien menunggu dalam sistem yaitu 92:05 $=5525$ menit/128 Pasien $=43,2$ Menit.

\section{Analisa Sistem Antrian Dengan Model Antrian Single Channel-Single Phase (M/M/1)}

Dalam penelitian ini penulis dapat menganalisa dengan menggunakan model antrian single channel single phase atau $\mathrm{m} / \mathrm{m} / 1$ untuk dapat melihat kinerja sistem antrian yang ada. Yang mana rumus telah dijelaskan pada bab 2 sebelumnya sebagai berikut :

$\lambda=$ Tingkat kedatangan rata-rata persatuan waktu

$\mu=$ Tingkat pelayanan rata-rata persatuan waktu

Pada jam 08.00 - 09.00 diketahui $\lambda=8 \mu=13$

a) Tingkat intensitas fasilitas pelayanan

$$
\mathrm{P}=\frac{\lambda}{\mu}=\frac{8}{13}=0,6154=61,54 \%
$$

b) Probabilitas terdapat 0 orang dalam sistem

$$
\mathrm{P} 0=1-\mathrm{P}=1-61,54 \%=0,3846=38,46 \%
$$

c) Jumlah rata - rata pasien dalam sistem

$$
\text { Ls }=\frac{P}{1-P}=\frac{0,6154}{1-0,6154}=\frac{0,6154}{0,3846}=1,6002 \text { pasien }
$$

d) Jumlah rata - rata pasien dalam antrian

$$
\mathrm{Lq}=\frac{\lambda}{\mu(\mu-\lambda)}^{2}=\frac{8}{13(13-8)}=\frac{64}{13(5)}=\frac{64}{65}=0,9847 \text { pasien }
$$

e) Waktu pasien berada dalam sistem

$$
\mathrm{Ws}=\frac{1}{\mu-\lambda}=\frac{1}{13-8}=\frac{1}{5}=0,2 \times 60 \text { menit }=12 \text { menit }
$$

f) Waktu pasien berada dalam antrian

$$
\mathrm{Wq}=\frac{\lambda}{\mu(\mu-\lambda)}=\frac{8}{13(13-8)}=\frac{8}{13(5)}=\frac{8}{65}=0,1230 \times 60 \text { menit }=7,4 \text { menit }
$$

Pada jam 09.00 -10.00 diketahui $\lambda=7 \mu=13$ 
a) Tingkat intensitas fasilitas pelayanan $\mathrm{P}=\frac{\lambda}{\mu}=\frac{7}{13}=0,5385=53,85 \%$

b) Probabilitas terdapat 0 orang dalam sistem

$\mathrm{P} 0=1-\mathrm{P}=1-53,85 \%=0,4615=46,15 \%$

c) Jumlah rata - rata pasien dalam sistem

Ls $=\frac{P}{1-P}=\frac{0,5385}{1-0,5385}=\frac{0,5385}{0,46,15}=1,1669$ pasien

d) Jumlah rata - rata pasien dalam antrian

$\mathrm{Lq}=\frac{\lambda}{\mu(\mu-\lambda)}^{2}=\frac{7}{13(13-7)}^{2}=\frac{49}{13(6)}=\frac{49}{78}=0,6283$ pasien

e) Waktu pasien berada dalam sistem

Ws $=\frac{1}{\mu-\lambda}=\frac{1}{13-7}=\frac{1}{6}=0,1667 \times 60$ menit $=10,002$ menit

f) Waktu pasien berada dalam antrian

$\mathrm{Wq}=\frac{\lambda}{\mu(\mu-\lambda)}=\frac{7}{13(13-7)}=\frac{7}{13(6)}=\frac{7}{78}=0,0898 \times 60$ menit $=5,388$ menit

\section{Pada jam 10.00 - 11.00 diketahui $\lambda=12 \mu=16$}

a) Tingkat intensitas fasilitas pelayanan

$\mathrm{P}=\frac{\lambda}{\mu}=\frac{12}{16}=0,75=75 \%$

b) Probabilitas terdapat 0 orang dalam sistem

$\mathrm{P} 0=1-\mathrm{P}=1-75 \%=0,25=25 \%$

c) Jumlah rata - rata pasien dalam sistem

Ls $=\frac{P}{1-P}=\frac{0,75}{1-0,75}=\frac{0,75}{0,25}=3$ pasien

d) Jumlah rata - rata pasien dalam antrian

$\mathrm{Lq}=\frac{\lambda}{\mu(\mu-\lambda)}^{2}=\frac{12}{16(16-12)}^{2}=\frac{144}{16(4)}=\frac{144}{64}=2,25$ pasien

e) Waktu pasien berada dalam sistem

$\mathrm{Ws}=\frac{1}{\mu-\lambda}=\frac{1}{16-12}=\frac{1}{4}=0,25 \times 60$ menit $=15$ menit

f) Waktu pasien berada dalam antrian

$\mathrm{Wq}=\frac{\lambda}{\mu(\mu-\lambda)}=\frac{12}{16(16-12)}=\frac{12}{16(4)}=\frac{12}{64}=0,1875 \times 60$ menit $=11,25$ menit

Pada jam 11.00 -12.00 diketahui $\lambda=19 \mu=22$

a) Tingkat intensitas fasilitas pelayanan

$\mathrm{P}=\frac{\lambda}{\mu}=\frac{19}{22}=0,8637=86,37 \%$

b) Probabilitas terdapat 0 orang dalam sistem

$\mathrm{P} 0=1-\mathrm{P}=1-86,37 \%=0,1363=13,63 \%$

c) Jumlah rata - rata pasien dalam sistem

$\mathrm{Ls}=\frac{\mathrm{P}}{1-\mathrm{P}}=\frac{0,8637}{1-0,8637}=\frac{0,8637}{0,1363}=6,3368$ pasien

d) Jumlah rata - rata pasien dalam antrian

$\mathrm{Lq}={\frac{\lambda^{2}}{\mu(\mu-\lambda)}}^{2}=\frac{19}{22(22-19)}^{2}=\frac{361}{22(3)}=\frac{361}{66}=5,4697$ pasien

e) Waktu pasien berada dalam sistem

$\mathrm{Ws}=\frac{1}{\mu-\lambda}=\frac{1}{22-19}=\frac{1}{3}=0,3333 \times 60$ menit $=19,998$ menit

f) Waktu pasien berada dalam antrian

$\mathrm{Wq}=\frac{\lambda}{\mu(\mu-\lambda)}=\frac{19}{22(22-19)}=\frac{19}{22(3)}=\frac{19}{66}=0,2879 \times 60$ menit $=17,274$ menit 
Pada jam 12.00 - 13.00 diketahui $\lambda=21 \mu=23$

a) Tingkat intensitas fasilitas pelayanan $\mathrm{P}=\frac{\lambda}{\mu}=\frac{21}{23}=0,9131=91,31 \%$

b) Probabilitas terdapat 0 orang dalam sistem $\mathrm{P} 0=1-\mathrm{P}=1-91,31 \%=0,0869=8,69 \%$

c) Jumlah rata - rata pasien dalam sistem Ls $=\frac{P}{1-P}=\frac{0,9131}{1-0,9131}=\frac{0,9131}{0,0869}=10,5075$ pasien

d) Jumlah rata - rata pasien dalam antrian $\mathrm{Lq}=\frac{\lambda}{\mu(\mu-\lambda)}^{2}=\frac{21}{23(23-21)}^{2}=\frac{441}{23(2)}=\frac{441}{46}=9,5870$ pasien

e) Waktu pasien berada dalam sistem Ws $=\frac{1}{\mu-\lambda}=\frac{1}{23-21}=\frac{1}{2}=0,5 \times 60$ menit $=30$ menit

f) Waktu pasien berada dalam antrian $\mathrm{Wq}=\frac{\lambda}{\mu(\mu-\lambda)}=\frac{21}{23(23-21)}=\frac{21}{23(2)}=\frac{21}{46}=0,4565 \times 60$ menit $=27,39$ menit

\section{Pada jam 13.00 - 14.00 diketahui $\lambda=17 \mu=19$}

a) Tingkat intensitas fasilitas pelayanan $\mathrm{P}=\frac{\lambda}{\mu}=\frac{17}{19}=0,8948=89,48 \%$

b) Probabilitas terdapat 0 orang dalam sistem $\mathrm{P} 0=1-\mathrm{P}=1-89,48 \%=0,1052=10,52 \%$

c) Jumlah rata - rata pasien dalam sistem Ls $=\frac{P}{1-P}=\frac{0,8948}{1-0,8948}=\frac{0,8948}{0,1052}=8,5058$ pasien

d) Jumlah rata - rata pasien dalam antrian $\mathrm{Lq}=\frac{\lambda}{\mu(\mu-\lambda)}^{2}=\frac{17}{19(19-17)}^{2}=\frac{289}{19(2)}=\frac{289}{38}=7,6053$ pasien

e) Waktu pasien berada dalam sistem $\mathrm{Ws}=\frac{1}{\mu-\lambda}=\frac{1}{19-17}=\frac{1}{2}=0,5 \times 60$ menit $=30$ menit

f) Waktu pasien berada dalam antrian $\mathrm{Wq}=\frac{\lambda}{\mu(\mu-\lambda)}=\frac{17}{19(19-17)}=\frac{17}{19(2)}=\frac{17}{38}=0,4474 \times 60$ menit $=26,844$ menit

\section{Pada jam $14.00-15.00$ diketahui $\lambda=16 \mu=17$}

a) Tingkat intensitas fasilitas pelayanan $\mathrm{P}=\frac{\lambda}{\mu}=\frac{16}{17}=0,9412=94,12 \%$

b) Probabilitas terdapat 0 orang dalam sistem $\mathrm{P} 0=1-\mathrm{P}=1-94,12 \%=0,0588=5,88 \%$

c) Jumlah rata - rata pasien dalam sistem Ls $=\frac{P}{1-P}=\frac{0,9412}{1-0,9412}=\frac{0,9412}{0,0588}=16,0069$ pasien

d) Jumlah rata - rata pasien dalam antrian $\mathrm{Lq}=\frac{\lambda}{\mu(\mu-\lambda)}^{2}=\frac{16}{17(17-16)}=\frac{256}{17(1)}=\frac{256}{17}=15,0589$ pasien

e) Waktu pasien berada dalam sistem Ws $=\frac{1}{\mu-\lambda}=\frac{1}{17-16}=\frac{1}{1}=1 \times 60$ menit $=60$ menit

f) Waktu pasien berada dalam antrian 
$\mathrm{Wq}=\frac{\lambda}{\mu(\mu-\lambda)}=\frac{16}{17(17-16)}=\frac{16}{17(1)}=\frac{16}{17}=0,9412 \times 60$ menit $=56,472$ menit

Pada jam $15.00-16.00$ diketahui $\lambda=4 \mu=5$

a) Tingkat intensitas fasilitas pelayanan $\mathrm{P}=\frac{\lambda}{\mu}=\frac{4}{5}=0,8=80 \%$

b) Probabilitas terdapat 0 orang dalam sistem $\mathrm{P} 0=1-\mathrm{P}=1-80 \%=0,2=20 \%$

c) Jumlah rata - rata pasien dalam sistem Ls $=\frac{\mathrm{P}}{1-\mathrm{P}}=\frac{0,8}{1-0,8}=\frac{0,8}{0,2}=4$ pasien

d) Jumlah rata - rata pasien dalam antrian $\mathrm{Lq}=\frac{\lambda}{\mu(\mu-\lambda)}^{2}=\frac{4}{5(5-4)}^{2}=\frac{16}{5(1)}=\frac{16}{5}=3,2$ pasien

e) Waktu pasien berada dalam sistem Ws $=\frac{1}{\mu-\lambda}=\frac{1}{5-4}=\frac{1}{1}=1 \times 60$ menit $=60$ menit

f) Waktu pasien berada dalam antrian $\mathrm{Wq}=\frac{\lambda}{\mu(\mu-\lambda)}=\frac{4}{5(5-4)}=\frac{4}{5(1)}=\frac{4}{5}=0,8 \times 60$ menit $=48$ menit

\section{KESIMPULAN}

Hasil penelitian dapat disimpulkan bahwaDengan metode single channel single phase berhasil dirancang program perhitungan, mampu menjawab permasalahan dan memberikan penanganan serta hasil coba yang didukung dengan perangkat lunak Visual Basic memperoleh keakuratan hingga 97\%. Prediksi keakuratan yang cukup tinggi pada apotik Rumah Sakit Tentara Padang dapat membantu pihak manajemen Rumah Sakit dalam menentukan penambahan loket pengambilan obat pada tahun berikutnya.

\section{REFERENCES}

Carvalho, A., and Belo, O. 2016. "Predicting waiting time in customer queuing systems". 2016 IEEE international conference on knowledge engineering and applications, ICKEA 2016,155-159. https://doi.org/10.1109/ICKEA.2016.7803010.

Eni, N., and Utami, I. T. 2016. "Analisis antrian dengan model single channel single phase service pada stasiun pengisian bahan bakar umum ( spbu ) i gusti”.12(2), 125-138.

Jaber.,and Hussein, A. 2015. "Performance study of Active Queue Management methods: Adaptive GRED, REDD, and GRED-Linear analytical model'. journal of king saud university -computer and information sciences, $27: 417$.

Lesti, M. D. 2017.“Analisis Efisiensi Waktu Layanan pada Dinas Kependudukan dan Pencatatan Sipil Kota Kediri dengan Multi Channel - Single Phase”. jurnal simkieconomic, Vol. 01 No. 07, ISSN : BBBB-BBBB, Tahun 2017.

Manin, P. A., and Tarantsev, A. A. 2011. "On some regularities in single-channel unclosed systems with two-phase service".journal of computer and systems sciences international, 50(3), 438-447. https://doi.org/10.1134/S1064230711030117 
Pughat, A., and Sharma, V. 2015. "Queue discipline analysis for dynamic power management in wireless sensor node". 2015 annual ieee india conference (INDICON), 1-5. https://doi.org/10.1109/INDICON.2015.7443670

Rahayu, U. S., Wasono, R., and Utami, T. W. 2016. "Analisis Sistem Antrian Model Multi Phase-Multi Channel Pada Sentra Pelayanan Kios 3 in 1 Bbplk Semarang”. seminar nasional pendidikan, sains dan teknologi fakultas matematika dan ilmu pengetahuan alam universitas muhammadiyah semarang, 323-330.

Shang, Y. H., Luo, H., and Yu, F. X. 2012. "A phase calibration method for single channel monopulse tracking systems based on curve fitting technique”. proceedings of the 2012 2nd international conference on instrumentation and measurement, computer, communication and control,IMCCC2012, 4-7. https://doi.org/10.1109/IMCCC.2012.142

Simanjuntak, E. (2016). Pengaruh Waktu Tunggu Petugas Pelayanan Rekam Medis Terhadap Kepuasan Pasien Di Pendaftaran Rawat Jalan Di Rsud . Dr . R . M . Djoelham. 1(1), 35-38.

Simanjuntak, M. (2016). Tinjauan Faktor - Faktor Yang Mempengaruhi Pendaftaran Rawat Jalan Di. Ilmiah Perekam Dan Informasi Kesehatan Imelda, 1(1), 21-28.

Vorakulpipat, C. 2015. "From hospital to patient's hand: aself-service device for checking patient status information using big data analysis". 476-479.

Wereh, H. S., Mekel, P. A., and Nelwan, O. 2014. "Analisis sistem antrian pada pt sinar pasifik internusa manado”. Emba, 2(2), 1371-1380.

Wresni, A., and Hendri. 2014. "Simulasi model antrian multiple channel single phase pada sistem pelayanan kasir first come first serve (studi kasus : giant hypermarket panam pekanbaru)".seminar nasional IENACO - 2014, ISSN: 2337-4349.

Xing, W., Li, S., and He, L. 2015. “Simulation model of supermarket queuing system”. 2015 : 8819 .

Yong, H. S., Hao, L., and Fa,X. Y. 2012."A phase calibration method for single channel monopulse tracking systems based on curve fitting technique”.2012:577.

\section{BIOGRAPHIES OF AUTHORS}

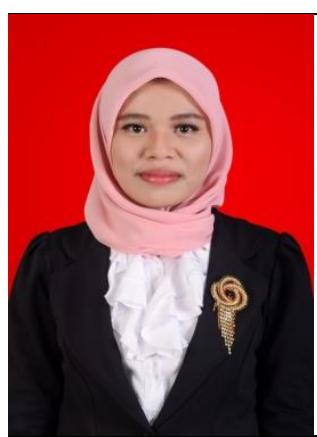

Yeyi Gusla Nengsih, Gelar Sarjana diperoleh dari Universitas Putra Indonesia YPTK Padang, Jurusan Ilmu Komputer pada Tahun 2017. Magister Ilmu Komputer diperoleh dari Universitas Putra Indonesia YPTK Padang pada Tahun 2018. Saat ini aktif sebagai pengajar di Program Studi D-III Perekam Medis dan Informasi Kesehatan Universitas Imelda Medan. 